\title{
Pasienter med personlighetsforstyrrelse i avtalepraksis
}

\begin{abstract}
BAKGRUNN Avtalepraksis er en viktig del av behandlingstilbudet innenfor den psykiatriske spesialisthelsetjenesten. Hvilken rolle avtalespesialister bør ha i behandlingen av pasienter med personlighetsforstyrrelse, er lite belyst. I denne undersøkelsen beskrives avtalespesialisters erfaringer med pasientgruppen og pasientenes tilfredshet med behandlingen.
\end{abstract}

MATERIALE OG METODE 46 pasienter ble henvist til avtalespesialist som ledd $\mathrm{i}$ en behandlingsstudie for personer med personlighetsforstyrrelse. 26 avtalespesialister deltok. Pasientpopulasjonen hadde omfattende problemer med høyt symptomnivå, relasjonelle vansker og dårlig arbeidsfunksjon. Pasientene ble etterundersøkt etter tre år. Terapeutene besvarte spørreskjemaer om egen praksis og pasientbehandlingen.

RESULTATER Ved tidspunktet for treårsundersøkelsen var en tredel av pasientene fortsatt $\mathrm{i}$ behandling. Mediant antall timer var 43 (spredning 2-258 t). Terapeutene opplevde i hovedsak behandlingene som faglig interessante, og majoriteten av pasientene var fornøyd med behandlingen. Enkelte behandlinger ble komplisert av uregelmessig oppmøte, rusmisbruk, selvmordsfare eller andre alvorlige symptomer. $29 \%$ av pasientene var misfornøyd med behandlingen, det gjaldt særlig dem med rusmisbruk.

FORTOLKNING Psykoterapi hos avtalespesialist gir mulighet for fleksibilitet med henblikk på behandlingslengde for pasienter med personlighetsforstyrrelse. Uttalte rusproblemer og utagerende atferd representerer en behandlingsmessig utfordring som kan være vanskelig å håndtere i avtalepraksis. Behandling i avtalepraksis forutsetter mulighet for akuttinnleggelse eller andre helsetjenester ved kriser og kompliserende rusmisbruk.

Pasienter med personlighetsforstyrrelser utgjør en stor andel av dem som behandles i den psykiatriske spesialisthelsetjenesten (1). Psykososial behandling, inkludert psykoterapi, er primærbehandlingen ved personlighetsforstyrrelse, og det er særlig pasienter med moderat og alvorlig personlighetsforstyrrelse som utgjør en behandlingsmessig utfordring. Disse har lavt funksjonsnivå, sammensatte problemer og behov for hjelp på mange områder i livet. Dette er gjerne unge voksne med et bredt spekter av symptomer, selvdestruktiv atferd, relasjonsproblemer og vanskeligheter med å fungere $\mathrm{i}$ studier og arbeid.

Flere internasjonale studier, deriblant norske, har vist at mange pasienter med personlighetsforstyrrelse har godt utbytte av individuell poliklinisk psykoterapi $(2,3)$. Man har som regel undersøkt behandling gitt i regi av offentlige poliklinikker eller universitetsklinikker. Avtalespesialistene er en viktig del av det samlede tilbudet innenfor den psykiatriske spesialisthelsetjenesten, men vi mangler kunnskap om behandling av pasienter med mer alvorlig personlighetspatologi i avtalepraksis, det vil si hos psykiater eller psykolog som er avtalespesialist.

Ullevål PersonlighetsProsjekt (UPP) er en randomisert studie der vi har undersøkt effekten av et spesialisert sykehusbasert behandlingsprogram for pasienter med moderat og alvorlig personlighetsforstyrrelse sammen- liknet med effekten av poliklinisk individualterapi.

Det var ingen forskjeller i utbytte mellom gruppene etter åtte og 18 måneder. Etter tre år hadde gruppen som var henvist til poliklinisk individualterapi et signifikant bedre psykososialt funksjonsnivå, mens etter seks år var det igjen ikke signifikante forskjeller mellom gruppene $(4,5)$. I begge grupper var det betydelig bedring.

Dette var uventede funn - da den opprinnelige hypotesen var at det sykehusbaserte programmet ville gi størst klinisk endring. $85 \%$ av pasientene som var randomisert til poliklinisk individualterapi, ble henvist til avtalespesialist. Funnene vakte nysgjerrighet når det gjaldt avtalespesialistenes og pasientenes erfaringer med denne behandlingen.

I denne undersøkelsen setter vi søkelys på behandlingen i avtalepraksis frem til treårsoppfølgingen. Formålet er å beskrive kjennetegn ved terapien og terapeutenes erfaringer med behandlingen og pasientenes tilfredshet med behandlingen.

\section{Materiale og metode}

Ullevål PersonlighetsProsjekt er en prospektiv longitudinell studie som utgår fra Seksjon for personlighetspsykiatri, Oslo universitetssykehus. Studien er godkjent av regional etisk komité for medisinsk forskningsetikk og av Datatilsynet.

Før behandling gjennomgikk alle pasien-

\author{
Theresa Wilberg \\ uxthwi@ous-hf.no \\ Forsknings- og utviklingsavdelingen \\ Klinikk psykisk helse og avhengighet \\ Oslo universitetssykehus, Aker \\ Elfrida Hartveit Kvarstein \\ Avdeling for personlighetspsykiatri \\ Oslo universitetssykehus, Ullevål \\ Jan Ole Røvik \\ Institutt for psykoterapi
}

Tl

Engelsk oversettelse på www.tidsskriftet.no

> Se lederartikkel side 2234

\section{HOVEDBUDSKAP}

Behandling hos avtalespesialist gir mulighet for fleksibel behandlingslengde og -intensitet for pasienter med personlighetsforstyrrelse

Majoriteten av pasientene er fornøyd med behandlingen

Uregelmessig oppmøte, rusmisbruk, alvorlige symptomer og utagerende atferd kompliserer behandlingen for et mindretall

Psykoterapi hos avtalespesialist forutsetter tilgjengelighet til andre helsetjenester ved symptomforverring og kompliserende rusmisbruk 
Tabell 1 Kjennetegn ved avtalespesialistene $(n=26)$. Median (spredning) dersom ikke annet er angitt

\begin{tabular}{|c|c|c|}
\hline Mannlige terapeuter (n) & 20 & \\
\hline Alder (år) & 58 & $(47-66)$ \\
\hline Psykiater (n) & 15 & \\
\hline Psykolog (n) & 11 & \\
\hline \multicolumn{3}{|l|}{ Psykoterapeutisk utdanning (n) } \\
\hline Norsk psykoanalytisk institutt & 4 & \\
\hline Institutt for psykoterapi & 17 & \\
\hline Institutt for vegetoterapi & 6 & \\
\hline Institutt for gruppeanalyse & 10 & \\
\hline Spesialtudanning i kognitiv terapi & 0 & \\
\hline Spesialutdanning i familieterapi & 8 & \\
\hline Annet & 13 & \\
\hline Antall års utdanning i individuell psykodynamisk terapi & 4 & $(1-12)$ \\
\hline Antall års utdanning i gruppeanalyse & 5 & $(1-6)$ \\
\hline Antall års utdanning i familieterapi & 2 & $(1-5)$ \\
\hline \multicolumn{3}{|c|}{ Grad av påvirkning fra ulike teoretiske retninger i arbeidet som terapeut (skala 0-5) } \\
\hline Analytisk/psykodynamisk & 4 & $(2-5)$ \\
\hline Kognitiv & 3 & $(1-5)$ \\
\hline Atferdterapeutisk & 2 & $(0-3)$ \\
\hline Antall år i arbeid som psykoterapeut & 24 & $(8-30)$ \\
\hline Tilfredshet i arbeidet som psykoterapeut (skala 0-5) & 4 & $(3-5)$ \\
\hline
\end{tabular}

tene en utredning foretatt av den kliniske staben ved avdelingen, heri inkludert strukturerte diagnostiske intervjuer og selvrapporte symptomer (4). Psykososial funksjon ble målt med det observatørbaserte instrumentet Global Assessment of Functioning (GAF) (6) på grunnlag av et intervju som var designet for prosjektet.

Etter tre år ble pasientene etterundersøkt av en forskningsassistent. GAF-vurderinger ble foretatt blindt for behandlingsbetingelse. Reliabiliteten av diagnostikk og GAF-skåring er funnet tilfredsstillende (4). Ved treårsundersøkelsen besvarte pasientene et spørsmål om hvor fornøyd de var med behandlingen. Svarene ble gradert på en skala fra 1 (svært misfornøyd) til 5 (svært fornøyd). Informasjon om annen behandling i treårsperioden er basert på pasientintervjuer ved tre etterundersøkelsestidspunkter ( 8 md.: $n=40$, 18 md.: $\mathrm{n}=32,3$ år: $\mathrm{n}=31$ ).

\section{Rekruttering av avtalespesialister}

Avtalespesialistene ble rekruttert ved skriftlig forespørsel til alle psykiatere og psykologer med avtalepraksis i Oslo i 2003/04. De ble spurt om de ville være med i en randomisert behandlingsstudie og kunne selv velge om de ville være terapeuter i det sykehusbaserte behandlingsprogrammet eller delta som terapeuter for pasienter randomisert til poliklinisk individualterapi.

De avtalespesialistene som deltok i den polikliniske behandlingen som omtales her, ble instruert til å behandle pasientene slik de vanligvis ville gjøre, uavhengig av deltakelse i prosjektet. De fikk verken instruksjoner om lengde, hyppighet av timeavtaler eller innhold i behandlingen. Terapeutene kunne også i tråd med sitt kliniske skjønn henvise pasienten til annen behandling dersom de anså dette som ønskelig. Begrunnelsen var at situasjonen skulle reflektere vanlig behandling gitt i avtalepraksis, snarere enn en spesiell form for psykoterapi, og som sådan representere et realistisk alternativ til det sykehusbaserte behandlingsprogrammet.

\section{Prosedyrer}

Avtalespesialistene oppga hvor mange prosjektpasienter de ønsket og når de kunne ta imot en pasient. Etter randomisering fikk de tildelt pasient etter liste, med beskjed om selv å kontakte vedkommende. Terapeutene fikk tilsendt resultatene av pasientens utredning ved avdelingen. Pasienten på sin side fikk oppgitt navnet på den tildelte terapeuten.

Ved inklusjon i prosjektet fylte avtalespesialistene ut et spørreskjema om utdanning og praksis og grad av tilfredshet $i$ arbeidet som psykoterapeut. Når pasienten sluttet $i$ behandling, fylte terapeuten ut et skjema om lengde og hyppighet av behandlingen, avslutningsgrunn, komplikasjoner og hvordan vedkommende selv hadde opplevd behandlingen. For de pasientene som ikke hadde avsluttet terapien ved tidspunktet for treårsundersøkelsen, fylte terapeutene ut et foreløpig behandlingsskjema.

To terapeuter, som til sammen behandlet tre pasienter, leverte ikke inn avslutningsskjema. Den ene var da død, den andre lot seg ikke oppspore.

\section{Avtalespesialistene}

Studien omfattet 26 avtalespesialister (tab 1). De hadde mange års erfaring som psykoterapeut og rapporterte høy grad av tilfredshet $\mathrm{i}$ sitt arbeid. På en skala fra 0 (ingen) til 5 (svært meget ) var median skår på spørsmålet om tilfredshet 4 (spredning 3-5). Terapeutene behandlet 1-3 prosjektpasienter hver.

\section{Pasientpopulasjonen}

46 pasienter ble henvist til avtalespesialist. Henvisning til avtalespesialist versus behandler ved distriktspsykiatrisk senter (DPS) eller liknende institusjoner var tilfeldig (fig 1). Én pasient møtte ikke til behandling og er utelatt fra analysene. 31 pasienter $(69 \%)$ deltok i oppfølgingsundersøkelsen etter tre år.

Det var ingen signifikante forskjeller mellom de som ikke deltok og de som deltok i treårsundersøkelsen med henblikk på sosiodemografiske forhold, diagnoser, opprinnelig symptombelastning eller arbeidsfunksjon, men de som ikke deltok, hadde signifikant lavere GAF-skår før behandlingen (gjennomsnitt 45,9 $(\mathrm{SD}=3,6)$ versus gjennomsnitt 49,3 $(\mathrm{SD}=5,0), \mathrm{p}=0,029)$. Median alder ved behandlingsstart var 29 år (spredning $20-53$ år). 31 var kvinner.

De hyppigst forekommende typer av personlighetsforstyrrelse var emosjonelt ustabil (19 pasienter), engstelig unnvikende (17 pasienter), paranoid (6 pasienter) og uspesifisert personlighetsforstyrrelse (11 pasienter). De hadde i tillegg depressive lidelser (40 pasienter), angstlidelser (37 pasienter) og alkohol- eller stoffmisbruk (15 pasienter). Det siste året før inklusjon i studien hadde $11 \mathrm{av}$ pasientene bedrevet selvskading, 38 pasienter hadde hatt selvmordstanker og seks hadde gjort selvmordsforsøk.

Median alder ved første gangs kontakt med hjelpeapparatet på grunn av psykiske 


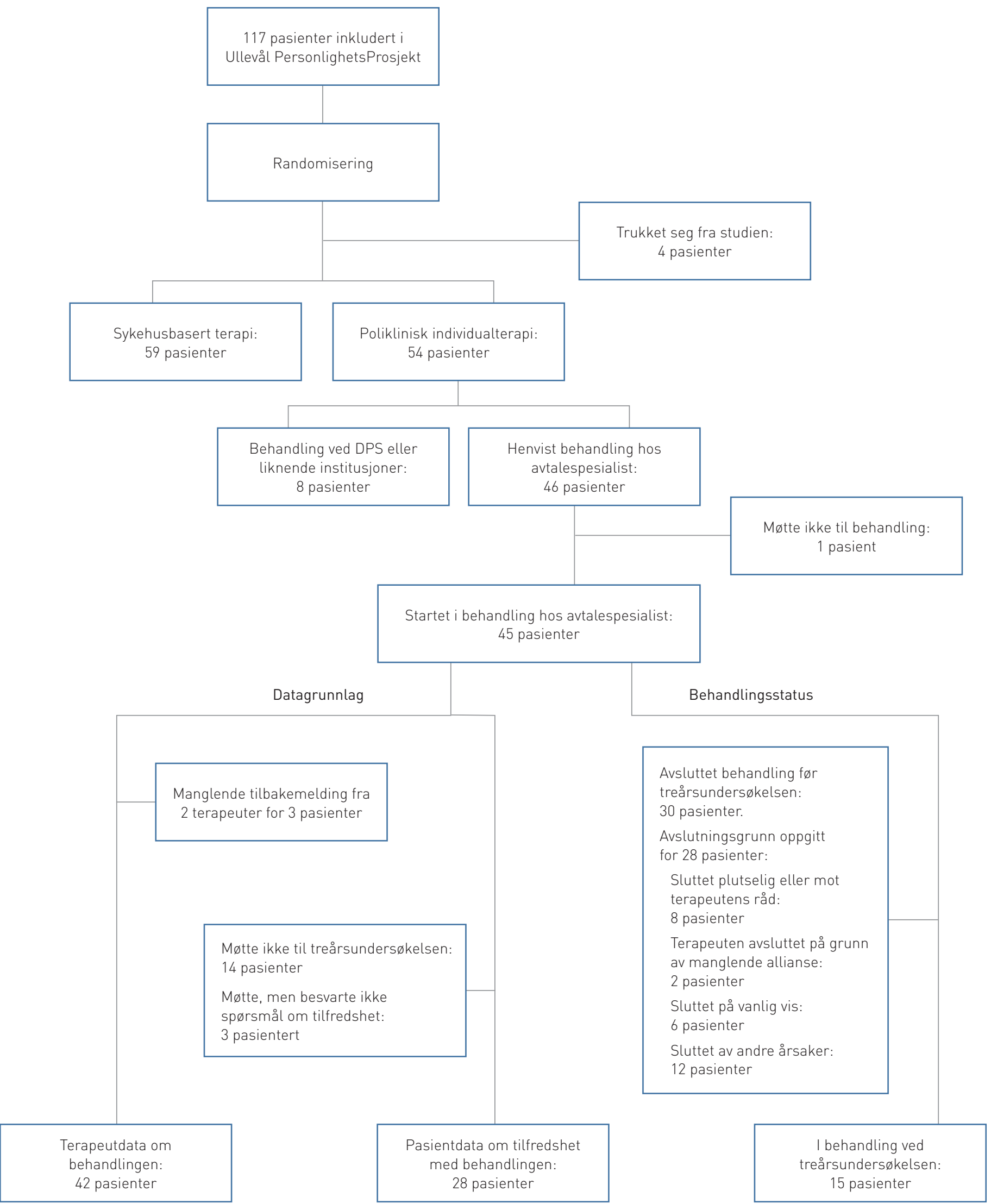

Figur 1 Pasientflyt, datagrunnlag og behandlingsstatus ved treårsundersøkelsen 
Tabell 2 Behandlingsmengde og avtalespesialistenes erfaringer med behandlingen (data fra 42 innleverte terapeutskjemaer). Median (spredning) dersom ikke annet er angitt

\begin{tabular}{|c|c|c|}
\hline Antall timer psykoterapi i treårsperioden & 43 & $(2-258)$ \\
\hline Pasienter med mindre enn 10 timer (n) & 8 & \\
\hline Pasienter med mer enn 80 timer (n) & 10 & \\
\hline \multicolumn{3}{|l|}{ Hyppighet av timer, mest karakteristisk for behandlingen (n) } \\
\hline Oftere enn 1 time pr uke & 6 & \\
\hline 1 time pr uke & 24 & \\
\hline Sjeldnere enn 1 time pr uke & 12 & \\
\hline \multicolumn{3}{|l|}{ Terapeutens vektlegging i behandlingen (skala $0-5$ ) } \\
\hline Innsikt/selvforståelse & 3 & $(0-5)$ \\
\hline Støtte/stabilisering & 4 & $(0-5)$ \\
\hline Problemløsning & 4 & $(0-5)$ \\
\hline \multicolumn{3}{|l|}{ Terapeutens opplevelse av behandlingen (skala 0-5) } \\
\hline Interessant og faglig stimulerende & 3 & $(0-5)$ \\
\hline God behandlingsallianse fra pasientens side & 3 & $(0-5)$ \\
\hline Krevende pga. alvorlig bekymring om pasientens utagerende atferd & 2 & $(0-5)$ \\
\hline Krevende pga. alvorlige bekymringer om suicidalfare & 1 & $(0-5)$ \\
\hline Krevende pga. stort behov for samarbeid med andre instanser & 0 & $(0-5)$ \\
\hline
\end{tabular}

Behandlingen ble komplisert av

Hyppige telefoner fra pasienten utenom timeavtale (n) 2

Pasienten møtte alkohol-/rus-/medikamentpåvirket til time (n)

4

Innleggelse i psykiatrisk akuttavd pga. suicidalfare (n)

Pasienten ble psykotisk (n)

Annet $(n)$ 4

1

Pasientens uteblivelser eller avlysninger representerte et alvorlig problem

for den behandlingsmessige stabiliteten (n)

Antall pasienter der terapeuten til en viss grad opplevde at behandlingen var vanskelig å forene med avtalepraksis på grunn av

$\emptyset$ konomisk tap knyttet til avlysning av timer (n)

12

Stort behov for samarbeid med andre instanser ( $\mathrm{n}$ ) plager var 21 år (spredning 2-45 år). 20 pasienter hadde hatt tidligere psykoterapi og 17 hadde vært innlagt i psykiatrisk døgnavdeling. Av de 42 som besvarte spørsmålet om arbeid, oppga 18 at de verken hadde studert eller arbeidet det siste året før undersøkelsen. Det dreier seg dermed om pasienter med langvarige og sammensatte plager og betydelige nedsatt arbeidsfunksjon.

\section{Statistiske analyser}

Det er angitt frekvenser, gjennomsnitt, median og spredning. Forholdet mellom dikotome variabler ble testet med khikvadrattest. Rela- sjoner mellom kontinuerlige og dikotome variabler ble testet med uavhengig t-test eller Mann-Whitneys test, mens korrelasjoner mellom kontinuerlige variabler ble undersøkt med Spearmans rho. Det er litt varierende antall $i$ analysene, grunnet manglende data.

\section{Resultater}

Psykoterapien og terapeutenes erfaringer Det vanligste var at pasientene gikk i behandling en time per uke (tab 2). En del terapeuter gikk etter en stund over til å se pasienten sjeldnere, eksempelvis hver annen uke eller med noen måneders mellomrom. Mediant antall timer i terapi ved treårsundersøkelsen var 43 timer (spredning 2-258 t). Åtte pasienter hadde hatt under ti timer terapi, mens ti hadde hatt mer enn 80 timer. 30 av totalt 45 pasienter hadde avsluttet behandlingen før treårsundersøkelsen (fig 1).

Terapeutene fant $\mathrm{i}$ hovedsak terapiene interessante og faglig stimulerende, med middels god behandlingsallianse for gruppen som helhet (tab 2). De rapporterte noe bekymring knyttet til utagerende atferd og suicidalitet.

Det var lite komplikasjoner i form av telefoner utenom timeavtale, at pasienten møtte ruspåvirket til timene eller innleggelse grunnet selvmordsfare, men for halvparten av pasientene rapporterte terapeuten andre typer komplikasjoner. De forholdene som hyppigst kompliserte behandlingen var uregelmessig oppmøte, pasientens dårlige funksjon, utagerende atferd, rusmisbruk eller alvorlige psykiske symptomer. For omtrent en firedel av pasientene var uteblivelser eller avlysning av timer et problem for behandlingsstabiliteten.

\section{Pasientenes tilfredshet med behandlingen}

Av de 28 pasientene som besvarte spørsmålet om tilfredshet med behandlingen, var ti fortsatt i terapi, mens 18 hadde sluttet. Årsak til avslutning var rapportert for 16 av disse pasientene: det var frafall hos fire (drop out), to behandlinger ble avsluttet av terapeuten på grunn av manglende allianse, fem pasienter sluttet på vanlig måte og fem av andre årsaker.

Det var ikke signifikante forskjeller i opprinnelig funksjonsnivå eller symptombelastning mellom de 28 som hadde besvart spørsmålet om tilfredshet og resten av totalmaterialet. 20 pasienter $(71 \%$ ) oppga at de var fra middels fornøyd til svært fornøyd med behandlingstilbudet, mens åtte $(29 \%)$ var misfornøyd eller svært misfornøyd.

Det var ingen signifikante sammenhenger mellom grad av tilfredshet og sosiodemografiske kjennetegn, psykososial funksjonssvikt eller symptombelastning før behandlingsstart, heller ikke med type personlighetsforstyrrelse eller symptomlidelser. Det var ett unntak: Pasienter med rusmisbruksdiagnose (alkohol- eller stoffmisbruk) ved behandlingsstart (8 av 28 pasienter) var signifikant mindre fornøyd enn pasienter uten rusmisbruk (gjennomsnitt 2,5 $(\mathrm{SD}=0,5)$ versus 3,6 $(\mathrm{SD}=1,4), \mathrm{p}=0,025$, på en skala fra 1 (svært misfornøyd) til 5 (svært fornøyd).

Pasientenes tilfredshet var verken korrelert med terapeutenes teoretiske orientering eller vektlegging av henholdsvis innsikt/selvforståelse, støtte/stabilisering eller problemløsning. Derimot var det negative korrelasjoner mellom pasienttilfredshet og terapeutens opplevelse av behandlingen som krevende på grunn av alvorlig bekymring for pasientens utagerende atferd (rho $=-0,56, \mathrm{p}=0,003$ ), 
alvorlig bekymring for selvmordsfare (rho = $-0,51, p=0,01)$, stort behov for samarbeid med andre instanser $($ rho $=-0,45, p=0,026)$ og at uteblivelser/avlysninger representerte et problem for behandlingsstabiliteten $(\mathrm{rho}=$ $-0,47, \mathrm{p}=0,018$ ).

På den annen side var det en positiv sammenheng mellom pasientens tilfredshet og terapeutens opplevelse av god behandlingsallianse fra pasientens side (rho $=0,58$, $\mathrm{p}=0,003)$ og mellom tilfredshet og bedring $\mathrm{i}$ GAF-skår i treårsperioden (rho $=0,56$, $\mathrm{p}=0,002)$. Selv når vi utelot fra analysen en pasient med et uvanlig høyt antall terapitimer $(258 \mathrm{t})$, var det en signifikant positiv korrelasjon mellom pasienttilfredhet og antall terapitimer (rho $=0,57, \mathrm{p}=0,004)$.

\section{Annen behandling}

Seks pasienter hadde vært innlagt 1-3 ganger i psykiatrisk døgnavdeling, to hadde døgnopphold på avlastningspost ved DPS, seks hadde vært på psykiatrisk legevakt og seks ble henvist til annen dagavdeling enn den ved Ullevål. Ved treårsundersøkelsen rapporterte ti av de 31 (32\%) etterundersøkte pasientene fast bruk av psykofarmaka, mot 25 av 43 pasienter ( $58 \%$ ) ved oppstart.

\section{Diskusjon}

Mediant antall terapitimer var 43, og en tredel av pasientene gikk fortsatt i terapi ved treårsundersøkelsen. En betydelig andel av pasientene fikk dermed et behandlingsomfang det kan være vanskelig å finne rom for ved distriktspsykiatriske poliklinikker. Likevel var det stor variasjon i behandlingsmengden, og en del hadde kun hatt få timer.

Det var en positiv sammenheng mellom antall terapitimer og pasientenes tilfredshet med behandlingen. Undersøkelsen viste også at behandlingen til en viss grad var preget av fleksibilitet når det gjaldt hyppighet av timer. En del terapier startet som ukentlige for så å gå over i en mindre intensiv fase. Kontinuiteten i den terapeutiske relasjonen ble dermed ivaretatt.

For mange pasienter med personlighetsforstyrrelse har tilknytningen til omsorgspersonene i oppveksten vært preget av utrygghet eller traumatiske forhold. Slike tilknytningserfaringer medvirker til de relasjonelle problemene pasienten har som voksen. Å kunne knytte seg til en terapeut som er stabil og forutsigbar over tid, kan derfor ha en spesiell betydning for disse pasientene og kan gi mulighet for å arbeide med sentrale problemer innenfor en trygg terapeutisk relasjon.

Pasienter med personlighetsforstyrrelse har en tendens til å involvere seg i negative samspill med andre på en måte som forsterker deres negative selvoppfatning, følelsesmes- sige ubalanse og opplevelse av avvisning. I denne undersøkelsen ble flere behandlinger komplisert av uregelmessig oppmøte, utagerende atferd, rusmisbruk eller bekymringer knyttet til pasientens suicidalitet, forhold som kan oppleves som krevende for terapeuter.

Med en del pasienter lyktes det ikke å etablere en tilstrekkelig god behandlingsallianse, og analysene av pasientenes tilfredshet indikerer at nettopp de med rusproblemer, mye utagerende atferd eller alvorlig suicidalitet representerer en behandlingsmessig utfordring som kan være vanskelig å håndtere $\mathrm{i}$ avtalepraksis.

Misfornøyde pasienter hadde svakere funksjonsbedring i løpet av de tre årene. Ut fra denne studien kan vi ikke si noe om hvorvidt dette reflekterer uheldige terapeutiske prosesser i denne eller senere behandlinger eller andre prognostiske kjennetegn ved pasientene. Likevel opplevde terapeutene i hovedsak at terapiene var interessante og faglig stimulerende.

Andelen pasienter som droppet ut av behandlingen, var ikke spesielt høy sammenliknet med internasjonale studier, der frafallsrater på godt over $30 \%$ er vanlig (7, 8). Ingen av dem som fortsatt var i terapi etter tre år vil bli kategorisert i gruppen frafall, slik at den endelige frafallsraten blir $\mathrm{i}$ underkant av $20 \%$.

Resultatene må tolkes med forsiktighet. De deltakende avtalespesialistene var selvselekterte til studien, og det er uklart hvor representative de var for avtalespesialister generelt. De var sannsynligvis godt motivert, og mange hadde lang erfaring, selv om de ikke nødvendigvis hadde spesiell erfaring med denne pasientgruppen. Noen terapeuter behandlet flere pasienter, slik at det er en viss avhengighet $\mathrm{i}$ dataene. Studiedesignen utelukket muligheten for å undersøke terapeuteffekter.

Pasientutvalget var representativt for pasienter henvist til tredjelinjetjenesten for behandling av personlighetsforstyrrelse, men resultatene kan ikke nødvendigvis generaliserers til pasienter med personlighetsforstyrrelse mer generelt. Videre ble en del pasienter innlagt til ulike typer døgnbehandling eller begynte $i$ annen terapi etter at de hadde avsluttet behandlingen hos avtalespesialisten. Vi vet ikke hvorvidt erfaringer fra annen behandling har innvirket på pasientenes rapportering av tilfredshet med prosjektbehandlingen.

Et hovedpoeng var imidlertid at ved kriser eller når eget behandlingstilbud ble vurdert som utilstrekkelig, støttet avtalespesialistene seg på annen tilgjengelig behandling. Dette burde være mulig mange steder i Norge med et godt utviklet og rimelig differensiert behandlingstilbud.

\section{Theresa Wilberg (f. 1955)}

er ph.d., spesialist i psykiatri med spesialkompetanse på personlighetsforstyrrelser og overlege. Hun er medlem av styret for den europeiske foreningen for studier av personlighetsforstyrrelser

Forfatter har fylt ut ICMJE-skjemaet og oppgir ingen interessekonflikter.

\section{Elfrida Hartveit Kvarstein (f. 1961)}

er ph.d., spesialist i psykiatri og enhetsleder/ overlege.

Forfatter har fylt ut ICMJE-skjemaet og oppgir ingen interessekonflikter.

\section{Jan Ole Røvik (f. 1960)}

er ph.d., spesialist i psykiatri, avtalespesialist og administrativ leder.

Forfatter har fylt ut ICMJE-skjemaet og oppgir ingen interessekonflikter.

\section{Litteratur}

1. Alnæs R, Torgersen S. DSM-III symptom disorders (Axis I) and personality disorders (Axis II) in an outpatient population. Acta Psychiatr Scand 1988; 78 348-55.

2. Svartberg M, Stiles TC, Seltzer MH. Randomized, controlled trial of the effectiveness of short-term dynamic psychotherapy and cognitive therapy for cluster $\mathrm{C}$ personality disorders. Am J Psychiatry 2004: 161: 810-7.

3. Nysæter TE, Nordahl HM, Havik OE. A preliminary study of the naturalistic course of non-manualized psychotherapy for outpatients with borderline per sonality disorder: Patient characteristics, attrition and outcome. Nord J Psychiatry 2010; 64: 87-93.

4. Gullestad FS, Wilberg T, Klungsøyr 0 et al. Is treatment in a day hospital step-down program superior to outpatient individual psychotherapy for patients with personality disorders? 36 months follow-up of a randomized clinical trial comparing different treatment modalities. Psychother Res 2012; 22: 426-41

5. Antonsen BT, Klungsøyr O, Kamps A et al. Stepdown versus outpatient psychotherapeutic treatment for personality disorders: 6-year follow-up of the Ullevål personality project. BMC Psychiatry 2014; 14: 119

6. Pedersen G, Hagtvet KA, Karterud S. Generalizability studies of the global assessment of functioning-split version. Compr Psychiatry 2007; 48: $88-94$

7. McMurran M, Huband N, Overton E. Non-completion of personality disorder treatments: a systematic review of correlates, consequences, and interventions. Clin Psychol Rev 2010; 30: 277-87.

8. Crawford MJ, Price K, Gordon F et al. Engagement and retention in specialist services for people with personality disorder. Acta Psychiatr Scand 2009; 119: 304-11.

Mottatt 6.12. 2013, første revisjon innsendt 27.6 2014, godkjent 15.10. 2014. Redaktør: Sigurd Høye. 